\title{
Situações de urgências e emergências entre adolescentes e adultos jovens: revisão integrativa da literatura
}

\section{Urgent and emergency situations among adolescents and young adults: an integrative literature review}

\author{
Paulo Cesar Teles Correia Júnior ${ }^{1}$, Maria Veraci Oliveira Queiroz ${ }^{1}$ \\ 1 - Universidade Estadual do Ceará - UECE, Fortaleza, CE, Brasil
}

\begin{abstract}
RESUMO
Introdução: adolescentes e jovens vivenciam uma fase da vida marcada por inúmeras vulnerabilidades que influenciam suas condições de saúde e os expõem a situações de urgências e emergências. Este artigo busca responder à pergunta: quais as principais situações de urgência e emergência entre adolescentes e adultos jovens observadas em estudos publicados? Objetivo: identificar as principais enfp.c.junior@gmail.com situações de urgência e emergência entre adolescentes e adultos jovens. Método: revisão integrativa elaborada a partir de artigos publicados nos últimos 10 anos (2010-2019), selecionados após busca pelos descritores "Adolescentes", "Primeiros Socorros" e "Urgência e Emergência", nas bases de dados Literatura Latino-Americana e do Caribe em Ciências da Saúde (LILACS), Banco de Dados em Enfermagem (BDENF) e Medical Literature Analysis and Retrieval System Online (MEDLI$\mathrm{NE}$ ), no período de junho a setembro de 2019. Realizou-se uma leitura minuciosa dos artigos. Os trabalhos que respondiam à pergunta norteadora da revisão foram selecionados, classificados e tabulados para análise e posterior síntese dos conhecimentos. Resultados: obteve-se um total de 15 artigos que revelaram, entre o público-alvo adolescente e jovem, situações de violência, acidentes de trânsito, quedas, intoxicação por drogas, tentativa de suicídio, engasgamentos e alguns casos clínicos, a saber: queimaduras, lacerações e acidentes com animais peçonhentos. Estas foram as causas predominantes dentre os atendimentos de urgência e emergência prestados a adolescentes e jovens.

Palavras-chave: Conclusão: as urgências e emergências identificadas podem ser evitadas e/ou amenizadas por meio Adolescentes; Adulto da Educação em Saúde e de políticas públicas voltadas para a promoção da saúde e a prevenção de Jovem; Emergências doenças e agravos.
\end{abstract}

\begin{abstract}
Introduction: adolescents and young people experience a phase of life marked by innumerable vulnerabilities that influence their health conditions and expose them to urgent and emergency situations. The aim of this article is to answer the question: What are the main urgent and emergency situations among adolescents and young adults observed in published studies? Objective: to identify the main urgent and emergency situations among adolescents and young adults. Method: an integrative review was conducted with articles published in the last 10 years (2010 to 2019), selected after searching for the descriptors "Adolescents", "First Aid" and "Urgency and Emergency" in the Latin American and Caribbean Health Sciences Literature database (LILACS), Nursing Database (BDENF) and Medical Literature Analysis and Retrieval System Online (MEDLINE), between June and September 2019. A thorough reading of the articles was carried out, those that answered the guiding question of the review were selected, classified and tabulated for data analysis and subsequent synthesis of knowledge. Results: a total of 15 articles were retrieved. They revealed situations of violence, traffic accidents, falls, drug intoxication, suicide attempt, choking and some clinical cases, such as burns, lacerations and accidents with venomous animals, among the adolescent and young adult target population. These were the predominant causes of urgent and emergency care among

Keywords: adolescents and young people. Conclusion: the urgencies and emergencies identified can be avoided
\end{abstract} Adolescents; Young Adult; or mitigated through health education and public policies aimed at preventing diseases and harm and Emergencies. promoting health. 


\section{INTRODUÇÃO}

Adolescentes e jovens são definidos pela Organização Mundial da Saúde (OMS) por meio de limites cronológicos das idades, dividindo-os nas faixas etárias de 10 a 19 anos para os adolescentes, e 20 a 24 para jovens adultos. Atualmente, tendese a agrupar ambas as faixas e denominá-las de adolescência e juventude ou adolescentes e jovens. Esta população não é compreendida apenas em termos etários, mas também em um sentido sociológico, como tempo de construção identitária e definição de projetos de vida futuros. Nesse sentido, a adolescência e a juventude são fases da vida muito marcadas por ambivalências. ${ }^{2}$

Esse público está em uma fase da vida repleta de riscos e vulnerabilidades que interferem nas suas condições de saúde, considerando as rápidas e intensas modificações nos campos biológico, fisiológico, emocional, familiar e social próprias à adolescência e à juventude. Essas experiências podem expor adolescentes e adultos jovens a inúmeras suscetibilidades, a exemplo do uso de drogas, da iniciação sexual precoce e desprotegida e da frequência a ambientes inseguros. Tais circunstâncias podem resultar em situações de urgências e emergências. ${ }^{3}$ A busca por novas referências e experiências pode implicar em atitudes de risco e exposição desses sujeitos às urgências e emergências - como acidentes e violências -, gerando um grave problema de Saúde Pública. ${ }^{4}$

As situações emergenciais por causas externas são o principal motivo de morbimortalidade em adolescentes e jovens, sendo estimadas pela OMS cerca de 875.000 mortes anuais ${ }^{5}$. As causas externas são definidas pela Classificação Internacional de Doenças e Problemas Relacionados à Saúde (CID) que, por sua vez, as classifica em: não intencional, intencional e evento de intenção indeterminada. Causa externa não intencional abrange acidente de trânsito, envenenamento acidental, quedas, exposição ao fogo, frio, afogamento, contato com calor, cobras, lagartos, aranhas, escorpiões, abelhas, vespas, complicações da assistência médica e outros. Causa externa intencional abarca suicídio, homicídio, guerra, intervenção legal e, por último, os eventos de intenção indeterminada. ${ }^{6}$ Além das causas externas explanadas, não devem ser esquecidas as causas clínicas e diversas, que aumentam ainda mais a problemática e realçam a relevância do tema.
A qualidade dos serviços de saúde para o atendimento às especificidades dos adolescentes e jovens precisa ser melhorada e qualificada, superando vários entraves. O primeiro deles é reconhecer a urgência e a relevância de se investir na adolescência e na juventude. ${ }^{3}$

Faz-se necessário que a população de adolescentes e jovens tenha acesso à informação de qualidade sobre aspectos relacionados à promoção da saúde e aos primeiros socorros, pois, de modo geral, expõem-se e são expostos a eventos com riscos de situações de urgência.

Com isso, sintetizou-se nesse artigo parte do conhecimento acerca das principais situações de urgência e emergência entre adolescentes e adultos jovens, possibilitando o direcionamento necessário ao desenvolvimento e à produção de tecnologia educativa de apoio às ações de prevenção e redução dos agravos e complicações decorrentes de tais ocorrências. O presente estudo teve como objetivo identificar as principais ocorrências de urgência e emergência entre adolescentes e adultos jovens discutidas nos trabalhos analisados.

\section{MÉTODO}

Trata-se de uma revisão integrativa da literatura, cuja finalidade é buscar a avaliação crítica e a síntese das evidências disponíveis acerca do assunto investigado, sendo o seu produto final o estado atual do conhecimento sobre a temática. ${ }^{7}$

$\mathrm{O}$ estudo em questão seguiu etapas estabelecidas, conforme a figura 1: identificação do tema e seleção da hipótese ou questão de pesquisa, estabelecimento de critérios para inclusão e exclusão de estudos, definição das informações a serem extraídas dos estudos selecionados, avaliação dos estudos incluídos na revisão integrativa, interpretação dos resultados e, por fim, apresentação da revisão/ síntese do conhecimento. ${ }^{7}$

Esse processo possibilitou a elaboração sintética de conhecimentos, a partir dos artigos analisados, quanto às principais ocorrências de urgências e emergências entre o público adolescente e jovem.

\section{Estabelecimento da hipótese ou questão de pesquisa}

Ao iniciar uma pesquisa, faz-se necessária uma questão norteadora, pois nesta estão as indagações 
em torno da questão central da pesquisa: o problema. Foram utilizados os componentes População/ pacientes; Intervenção; Comparação/controle e Desfecho/Outcome (PICO) para construir a questão norteadora. ${ }^{8}$ Esses componentes são fundamentais na elaboração da pergunta problema porque possibilitam a busca por evidências de maneira organizada, com foco no propósito, e evitam digressões desnecessárias.

O quadro 1 apresenta o acrônimo e a definição dos componentes da estratégia PICO, com a descrição do modo como construiu-se a pergunta de pesquisa.

Quadro 1 - Acrônimo, definição e descrição da estratégia PICO

\begin{tabular}{|c|c|c|}
\hline Acrônimo & Definição & Descrição \\
\hline $\mathrm{P}$ & $\begin{array}{c}\text { Paciente ou } \\
\text { problema }\end{array}$ & Adolescentes e Adultos Jovens \\
\hline $\mathrm{I}$ & Intervenção & $\begin{array}{c}\text { Estudos sobre Urgências e } \\
\text { Emergências }\end{array}$ \\
\hline $\mathrm{C}$ & $\begin{array}{c}\text { Controle ou } \\
\text { Comparação }\end{array}$ & Não se aplica \\
\hline $\mathrm{O}$ & $\begin{array}{c}\text { Outcome } \\
\text { (Desfecho) }\end{array}$ & $\begin{array}{c}\text { Principais situações de urgência e } \\
\text { emergência entre adolescentes e } \\
\text { jovens }\end{array}$ \\
\hline
\end{tabular}

Ressalta-se que se tratando de revisão integrativa, não foi possível contemplar, nesse texto, o terceiro elemento (comparison), pois nem todos os estudos incluídos no corpus possibilitaram respostas para esse acrônimo. Assim, definiu-se o problema da pesquisa: quais as principais situações de urgência $e$ emergência entre adolescentes e adultos jovens observadas em estudos publicados?

\section{Amostragem ou busca em literatura}

Nesta etapa, foram definidos os critérios de inclusão e exclusão dos artigos que compõem a revisão, bem como as estratégias utilizadas para as buscas nas bases de dados selecionadas. A pesquisa teve início em junho de 2019 e se estendeu até setembro do mesmo ano, tendo como critérios de inclusão dos artigos as seguintes condições: a) se estavam disponíveis integralmente, nas línguas portuguesa, inglesa e/ou espanhola; e b) se haviam sido publicados na década 2010-2019. Optou-se por esse período devido à obtenção de melhores índices de quantidade e qualidade na amostra. Foram excluídos artigos sem a identificação do autor e artigos que não abordavam diretamente o tema da revisão. Os textos

Figura 1 - Componentes da revisão integrativa de literatura

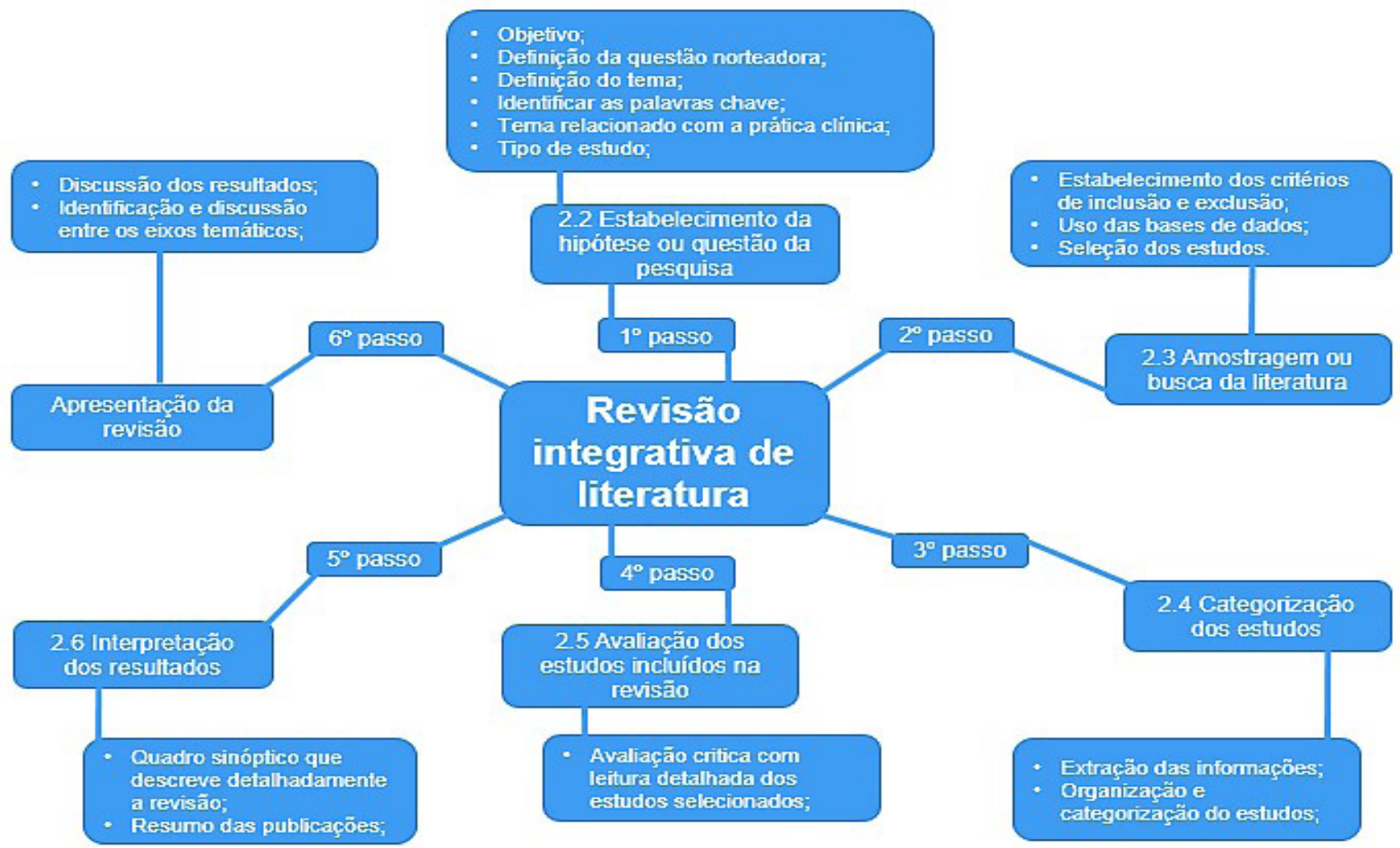

Fonte: Adaptada de: Mendes KDS, Silveira RCCP, Galvão CM. ${ }^{7}$

Rev. Interdisciplin. Promoç. Saúde - RIPS, Santa Cruz do Sul, 3(3):118-129, jul/set. 2020 ISSN: 2595-3664 
duplicados, disponíveis em mais de uma base de dados, foram contabilizados apenas uma vez.

O levantamento das publicações científicas foi realizado de forma online nas seguintes plataformas: Portal de Periódicos da Coordenação de Aperfeiçoamento de Pessoal de Nível Superior (CAPES/MEC) e Portal Biblioteca Nacional de Medicina dos Estados Unidos (PUBMED), em suas respectivas bases de dados: Literatura LatinoAmericana e do Caribe em Ciências da Saúde (LILACS), Base de Dados da Enfermagem (BDENF) e Medical Literature Analysis and Retrieval System Online (MEDLINE). No processo de busca, foram cruzados os descritores "Adolescentes", "Primeiros Socorros" e "Urgência e Emergência", obtidos no Descritores em Ciências da Saúde (DeCS), além de Teenager e Urgency, obtidos no Medical Subject Headings (MeSH), a partir dos quais pretendeuse ampliar os espectros da pesquisa e dilatar os conhecimentos sobre o objeto de estudo com vistas à elaboração de uma Cartilha Digital. Utilizou-se, ainda, o operador booleano $A N D$ para selecionar o maior número possível de trabalhos sobre a temática.
Quadro 2 - Estratégias de busca nas bases de dados eletrônicas com seus respectivos descritores

\begin{tabular}{|c|c|c|}
\hline Portal & Base de dados & Estratégia de Busca/Descritores \\
\hline $\begin{array}{c}\text { CAPES/ } \\
\text { MEC }\end{array}$ & $\begin{array}{c}\text { LILACS, } \\
\text { BDENF }\end{array}$ & $\begin{array}{c}\text { Adolescentes } \boldsymbol{A N D} \text { Primeiros } \\
\text { Socorros } \boldsymbol{A} \boldsymbol{N} \boldsymbol{D} \text { Urgência e } \\
\text { Emergência }\end{array}$ \\
\hline PUBMED & MEDLINE & Teenager $\boldsymbol{A N D}$ Urgency \\
\hline
\end{tabular}

\section{Categorização dos artigos}

Após a aplicação dos critérios de inclusão e exclusão, a seleção dos estudos progrediu para a fase de leitura de seus títulos, na qual buscou-se as literaturas diretamente relacionadas à temática investigada. Após essa etapa, ocorreu a leitura dos resumos de artigos selecionados, grupo onde foram incluídos apenas aqueles textos que apresentaram resposta à pergunta norteadora da revisão. Foram excluídos trabalhos de revisão, relatos de caso, dissertações, teses, capítulos de livros, editoriais e textos não científicos.

A figura 2 mostra o fluxograma que, segundo as recomendações PRISMA (Preferred Reporting Items for Systematic Reviews and Meta-Analyses/ Principais Itens para Relatar Revisões Sistemáticas e Metanálises), resume as estratégias de busca e os

Figura 2 - Fluxograma de seleção dos artigos encontrados nas bases de dados, segundo PRISMA

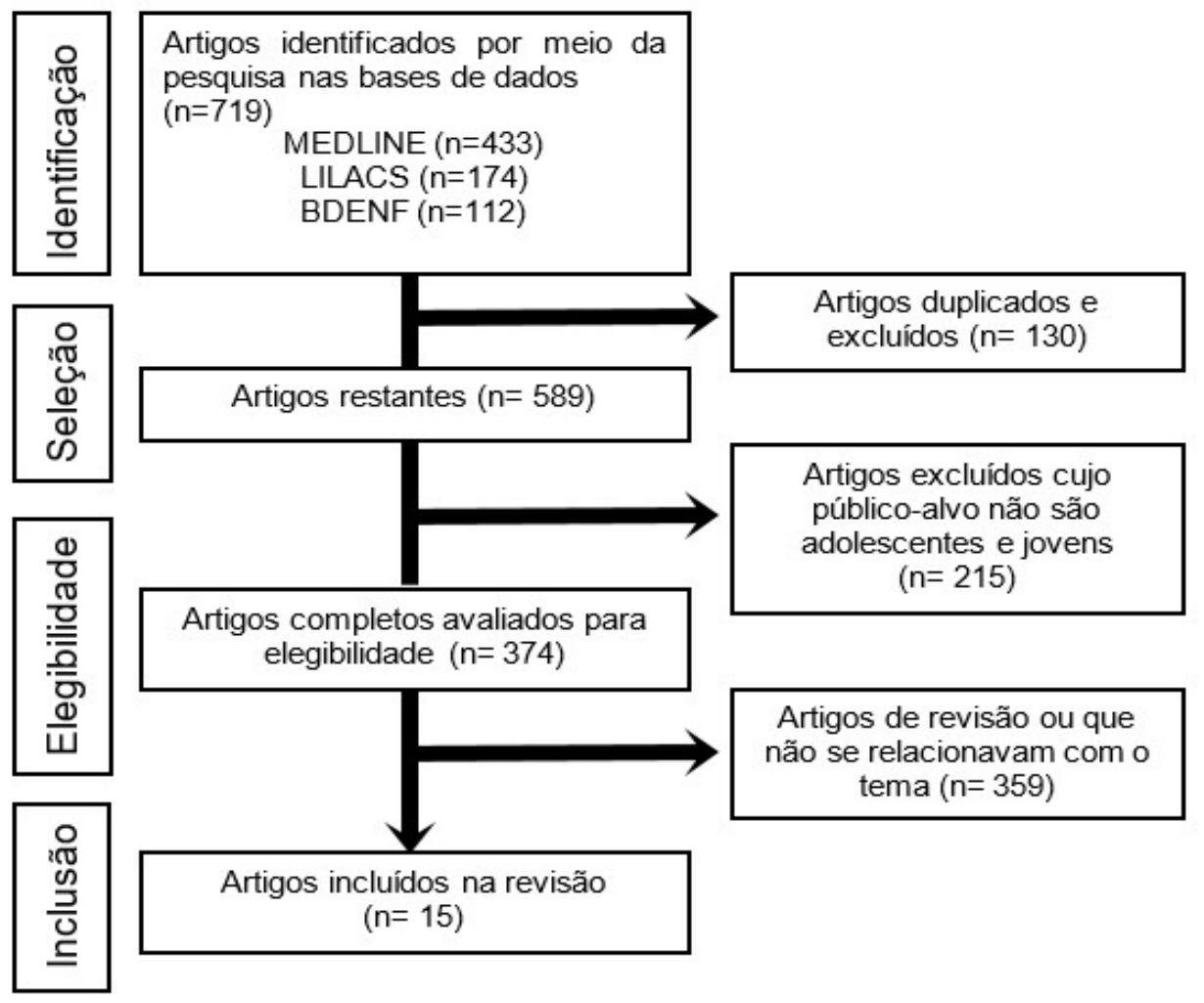

Fonte: Galvão TF, Pansani TSA. ${ }^{9}$ 
quantitativos de artigos encontrados em cada base de dados, além de informar o número de trabalhos excluídos e o porquê de não estarem de acordo com os critérios de inclusão, indicando a quantidade final de estudos para revisão. ${ }^{9}$

Foram realizados cruzamentos entre os descritores nas bases de dados. Os melhores resultados de busca foram obtidos com a configuração demonstrada no quadro 2. No portal CAPES, nas bases de dados LILACS e BDENF, os descritores "Adolescentes", "Primeiros Socorros" e "Urgência e Emergência" foram combinados entre pares e, por fim, os três. Desse modo, foram encontrados 286 trabalhos, publicados no último decênio, que continham palavras, em seus títulos ou textos, relacionadas ao problema desse estudo. No portal PUBMED, na base de dados MEDLINE, a combinação dos descritores Teenager e Urgency resultou em 433 publicações. Após a aplicação dos critérios de inclusão e exclusão, restaram seis artigos na LILACS, quatro artigos na BDENF e cinco artigos na MEDLINE, totalizando 15 publicações selecionadas para compor a revisão integrativa, tendo em vista que conformavam alguma aproximação ou semelhança com o objetivo da pesquisa e sua pergunta-problema.

\section{Descrição dos artigos}

Realizou-se uma leitura dos títulos de cada artigo, procurando identificar seu relacionamento com a temática investigada. Após essa identificação, procedeu-se à leitura dos resumos com a intenção de averiguar a ocorrência de possíveis "respostas" à pergunta orientadora da revisão. Feita uma leitura minuciosa dos artigos, eles foram ranqueados e classificados por meio de um instrumental ${ }^{10}$ devidamente validado, permitindo a organização e a tabulação dos dados para posterior interpretação e síntese dos conhecimentos. A fim de apresentar os estudos incluídos, foram desenvolvidos quadros para organizar e sintetizar as informações a partir da adaptação de instrumentos já validados em pesquisas semelhantes. ${ }^{10}$

Assim, foram reunidas as seguintes categorias de cada artigo: autoria, ano e local de publicação, método, objetivos e principais resultados. Segue-se com a discussão dos resultados e sua análise crítica relacionando-os com o cuidado educativo de adolescentes e jovens em situações de urgência e emergência.

\section{RESULTADOS}

Entre os 15 artigos selecionados, obteve-se a seguinte distribuição por ano de publicação: 2012 (dois), 2014 (dois), 2015 (um), 2016 (três), 2017 (quatro), 2018 (um) e 2019 (dois). Em relação aos países onde as pesquisas foram realizadas, destaca-se a predominância do Brasil com 10 artigos, seguido pelos Estados Unidos da América/EUA (três artigos), além de Portugal e Coreia do Sul (ambos com um artigo, cada).

A seguir, o quadro 3 demonstra os artigos selecionados e sua classificação segundo título, autoria, ano, país de publicação, delineamento metodológico e idade da população-alvo com os respectivos percentuais de adolescentes e jovens contemplados.

No quadro 4, foram sintetizados os artigos selecionados levando em consideração os objetivos de cada pesquisa, principais resultados encontrados nos estudos e, finalmente, a categorização das urgências e emergências mais recorrentes entre o público adolescente e jovem contemplado em cada investigação. Todos os dados foram extraídos do corpus da revisão.

\section{DISCUSSÃO}

Dos achados contemplados na revisão, observa-se, por meio do quadro 3 , que o público adolescente e jovem compõe $100 \%$ da população em seis estudos (artigos 5, 9, 12, 13, 14 e 15). Nos demais, há uma variação entre $20 \%$ e $90 \%$ de adolescentes e jovens na amostra (artigos 1, 2, 3, 4, 6, 7, 8, 10 e 11). Tal dado revela que esse público-alvo é largamente identificado em situações de urgência e emergência. Porém, aparentemente, são escassos os estudos sobre a temática voltados exclusivamente para as faixas etárias que compreendem adolescentes e adultos jovens.

A maioria dos artigos selecionados são recentes, considerando que, dentre os 15, 11 foram publicados nos últimos cinco anos, o que parece sugerir o crescimento do interesse pelas questões de saúde da população adolescente e jovem. Observou-se a predominância de estudos do tipo transversal, documental e/ou retrospectivo. Essas opções metodológicas parecem conformar modos de pesquisar que favorecem a obtenção de uma variedade de informações sobre os tempos passados e presentes de forma prática, rápida e precisa. ${ }^{23} \mathrm{Os}$ pesquisadores, em sua maioria, utilizaram bancos de dados eletrônicos sobre agravos em urgências e emergências para realizar seus estudos. 
Quadro 3 - Descrição dos estudos incluídos na revisão integrativa, segundo título, autoria, ano de publicação, país, delineamento do estudo e idade da população $\mathrm{n}=15$

\begin{tabular}{|c|c|c|c|c|}
\hline $\begin{array}{l}\mathbf{N}^{\circ} \text { do } \\
\text { Artigo }\end{array}$ & Título & Autoria, ano e país & $\begin{array}{c}\text { Tipo de pesquisa ou } \\
\text { delineamento metodológico }\end{array}$ & Idade da população-alvo \\
\hline 1 & $\begin{array}{l}\text { Acidentes domiciliares por forças mecânicas inanimadas em crianças, } \\
\text { adolescentes e jovens }\end{array}$ & $\begin{array}{l}\text { Brito, Pedroso e Martins } \\
\quad(\text { Brasil, 2016) }\end{array}$ & Transversal & $\begin{array}{c}0 \text { a } 24 \text { anos } \\
22 \% \text { de adolescentes e jovens }\end{array}$ \\
\hline 2 & $\begin{array}{l}\text { Quedas acidentais nos atendimentos de Urgência e emergência: resultados do } \\
\text { Viva Inquérito, de } 2014\end{array}$ & Ribeiro et al. (Brasil, 2016) ${ }^{11}$ & Epidemiológico & $\begin{array}{l}0 \text { a } 60 \text { anos } \\
41 \% \text { de adolescentes e jovens }\end{array}$ \\
\hline 3 & $\begin{array}{c}\text { Acidentes de transporte de crianças e adolescentes em serviço de emergência } \\
\text { de hospital de ensino, zona sul da cidade de São Paulo }\end{array}$ & Gorios et al. (Brasil, 2014) $)^{12}$ & Observacional/ Descritivo & $\begin{array}{l}0 \text { a } 19 \text { anos } \\
75 \% \text { de adolescentes e jovens }\end{array}$ \\
\hline 4 & $\begin{array}{l}\text { Perfil dos acidentes motociclísticos atendidos pelo serviço de atendimento } \\
\text { móvel de urgência nos anos de } 2014 \text { e } 2015 \text { em município baiano }\end{array}$ & Dantas et al. (Brasil, 2019) $)^{13}$ & Epidemiológico & $\begin{array}{c}2 \text { a } 73 \text { anos } \\
53 \% \text { de adolescentes e jovens }\end{array}$ \\
\hline 5 & $\begin{array}{c}\text { Causas externas em adolescentes: atendimentos em serviços sentinelas de } \\
\text { urgência e emergência nas capitais brasileiras - } 2009\end{array}$ & Malta et al. (Brasil, 2012) ${ }^{3}$ & Transversal & $\begin{array}{c}10 \text { a } 19 \text { anos } \\
100 \% \text { de adolescentes e jovens }\end{array}$ \\
\hline 6 & $\begin{array}{l}\text { Atendimentos por causas acidentais em serviços públicos de emergência - } \\
\text { Teresina, Piauí - } 2009\end{array}$ & Pedrosa et al. (Brasil, 2012) ${ }^{14}$ & Transversal & $\begin{array}{c}0 \text { a } 60 \text { anos } \\
61 \% \text { de adolescentes e jovens }\end{array}$ \\
\hline 7 & $\begin{array}{l}\text { Perfil clínico-epidemiológico dos pacientes da unidade de terapia intensiva } \\
\text { pediátrica de um hospital referência em trauma na Amazônia }\end{array}$ & Lima et al. (Brasil, 2016) $)^{15}$ & Retrospectivo & $\begin{array}{c}0 \text { a } 14 \text { anos } \\
25 \% \text { de adolescentes e jovens }\end{array}$ \\
\hline 8 & Tentativa de suicídio infanto-juvenil: lesão da parte ou do todo? & Alves e Cadete (Portugal, 2015) $)^{5}$ & Documental & $\begin{array}{c}0 \text { a } 18 \text { anos } \\
90 \% \text { de adolescentes e jovens }\end{array}$ \\
\hline 9 & $\begin{array}{l}\text { Violências contra adolescentes nas capitais brasileiras, segundo inquérito em } \\
\text { serviços de urgência }\end{array}$ & Malta et al. (Brasil, 2017) ${ }^{4}$ & Transversal & $\begin{array}{c}10 \text { a } 19 \text { anos } \\
100 \% \text { de adolescentes e jovens }\end{array}$ \\
\hline 10 & $\begin{array}{c}\text { Sistema de vigilância de violências e acidentes/VIVA e a notificação da } \\
\text { violência infanto-juvenil, no sistema único de saúde/SUS de Feira de Santa- } \\
\text { na-Bahia, Brasil }\end{array}$ & Souza et al. (Brasil, 2014) $)^{16}$ & Epidemiológico & $\begin{array}{l}0 \text { a } 18 \text { anos } \\
100 \% \text { de adolescentes e jovens }\end{array}$ \\
\hline 11 & $\begin{array}{l}\text { Perfil epidemiológico do atendimento por violência nos serviços públicos de } \\
\text { urgência e emergência em capitais brasileiras, Viva } 2014\end{array}$ & $\begin{array}{l}\text { Souto et al. } \\
\left(\text { Brasil, 2017) }{ }^{17}\right.\end{array}$ & Epidemiológico & $\begin{array}{l}0 \text { a } 60 \text { anos } \\
50 \% \text { de adolescentes e jovens }\end{array}$ \\
\hline 12 & $\begin{array}{l}\text { Características dos adolescentes que visitam o departamento de emergência } \\
\text { após tentativas de suicídio: estudo comparativo entre adolescentes e adultos }\end{array}$ & Lee et al. (Coreia do Sul, 2019) ${ }^{18}$ & Comparativo & $\begin{array}{c}10 \text { a } 18 \text { anos } \\
100 \% \text { de adolescentes e jovens }\end{array}$ \\
\hline 13 & \begin{tabular}{|l} 
Agressões não fatais entre pessoas de 10 a 24 anos - Estados Unidos, 2001- \\
2015 \\
\end{tabular} & David-Ferdon et al. (EUA, 2018) ${ }^{19}$ & Documental & $\begin{array}{c}10 \text { a } 24 \text { anos } \\
100 \% \text { de adolescentes e jovens }\end{array}$ \\
\hline 14 & $\begin{array}{l}\text { O uso indevido de opioides no departamento de emergência aumenta o } \\
\text { número de adolescentes e adultos jovens }\end{array}$ & $\begin{array}{c}\text { Abbasi } \\
(\text { EUA, 2017) } \\
\end{array}$ & Transversal & $\begin{array}{c}10 \text { a } 24 \text { anos } \\
100 \% \text { de adolescentes e jovens }\end{array}$ \\
\hline 15 & $\begin{array}{c}\text { Serviço de Urgências e Uso Hospitalar entre adolescentes com envolvimento } \\
\text { no Sistema Judicial }\end{array}$ & Winkelman et al. (EUA, 2017) ${ }^{21}$ & Transversal & $\begin{array}{c}12 \text { a } 17 \text { anos } \\
100 \% \text { de adolescentes e jovens }\end{array}$ \\
\hline
\end{tabular}

Fonte: Adaptado de: Garcia APRF, Freitas MIP, Lamas JLT, Toledo VP. ${ }^{10}$

Rev. Interdisciplin. Promoç. Saúde - RIPS, Santa Cruz do Sul, 3(3):118-129, jul/set. 2020 ISSN: 2595-3664 


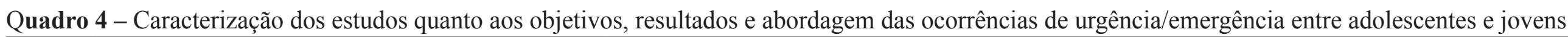

\begin{tabular}{|c|c|c|c|}
\hline $\begin{array}{l}N^{0} \text { do } \\
\text { Artigo }\end{array}$ & Objetivos & Resultados & $\begin{array}{l}\text { Abordagens das urgências e } \\
\text { emergências entre o público } \\
\text { adolescente e jovem }\end{array}$ \\
\hline 1 & $\begin{array}{l}\text { Analisar o perfil dos atendimentos de urgência e emergência } \\
\text { decorrentes de acidentes domiciliares causados por forças } \\
\text { mecânicas inanimadas na população infantojuvenil. }\end{array}$ & $\begin{array}{l}\text { A introdução de corpo estranho em orifícios naturais foi o tipo de acidente que prevaleceu em } \\
\text { todas as faixas etárias. Na faixa etária de } 15 \text { a } 19 \text { anos também houve um número considerável } \\
\text { de acidentes por contato com vidro cortante }(16,2 \%) \text { e por esmagamento entre objetos }(16,2 \%) \text {. }\end{array}$ & $\begin{array}{l}\text { Causas Diversas } \\
\text { Obstrução das vias aéreas } \\
\text { (corpo estranho), lacerações e } \\
\text { esmagamento. }\end{array}$ \\
\hline 2 & $\begin{array}{l}\text { Analisar os casos de quedas atendidos em unidades de urgência } \\
\text { e emergência de } 24 \text { capitais e Distrito Federal participantes do } \\
\text { VIVA Inquérito de } 2014 \text {. }\end{array}$ & $\begin{array}{l}\text { No perfil das vítimas de quedas, predominam o sexo masculino e as faixas etárias de } 0 \text { a } 9 \text { anos } \\
\text { e de } 20 \text { a } 39 \text { anos; } 56 \% \text { caíram da própria altura e a via pública foi o local mais frequente de } \\
\text { ocorrência; } 92,7 \% \text { das pessoas atendidas sofreram algum tipo de lesão física e entre elas as mais } \\
\text { comuns foram contusão, entorse e luxação, seguidas por corte/laceração. }\end{array}$ & $\begin{array}{l}\text { Causas Externas Quedas, } \\
\text { contusões, entorses e lacerações. }\end{array}$ \\
\hline 3 & $\begin{array}{l}\text { Descrever o perfil das vítimas e as circunstâncias dos acidentes } \\
\text { de transporte ocorridos com crianças e adolescentes atendidos } \\
\text { em hospital-escola na Zona Sul da cidade de São Paulo. }\end{array}$ & $\begin{array}{l}\text { Os acidentes de transporte entre crianças e adolescentes foram maiores em pessoas do sexo } \\
\text { masculino. Os principais acidentes atendidos na urgência foram ocasionados por automóveis } \\
\text { e motocicletas. A maior parte das vítimas foi atendida por atropelamento, lesão e trauma } \\
\text { superficial da cabeça, seguidos por trauma múltiplo não especificado em ambos os sexos. }\end{array}$ & $\begin{array}{c}\text { Causas Externas } \\
\text { Acidentes, traumatismo } \\
\text { cranioencefálico (TCE), traumas } \\
\text { e lacerações. }\end{array}$ \\
\hline 4 & $\begin{array}{l}\text { Descrever o perfil dos acidentes motociclísticos atendidos pelo } \\
\text { SAMU nos anos de } 2014 \text { e } 2015 \text { em município baiano quanto às } \\
\text { características da vítima, do atendimento, do evento e das lesões } \\
\text { sofridas. }\end{array}$ & $\begin{array}{c}\text { Os acidentes motociclísticos predominam entre homens }(71,7 \%) \text { na faixa etária de } 20 \text { a } 29 \text { anos } \\
(36,1 \%) \text {. Observou-se o sub-registro quanto ao uso do capacete. As lesões mais frequentes foram } \\
\text { escoriações em múltiplos locais }(61,6 \%) \text { e ferimento cortocontuso nos membros inferiores } \\
(40,8 \%) .\end{array}$ & $\begin{array}{l}\text { Causas Externas } \\
\text { Acidentes, traumas, cortes e } \\
\text { lacerações. }\end{array}$ \\
\hline 5 & $\begin{array}{l}\text { Analisar as ocorrências de causas externas em adolescentes } \\
\text { de } 10 \text { a } 19 \text { anos atendidos em serviços-sentinela de urgência e } \\
\text { emergência no Brasil. }\end{array}$ & $\begin{array}{c}6.434(89,8 \%) \text { adolescentes foram vítimas de acidentes e } 730(10,2 \%) \text { de violências. As } \\
\text { principais causas de acidentes foram as quedas, outros acidentes e o trânsito. Entre as violências, } \\
\text { predominaram as agressões. }\end{array}$ & $\begin{array}{l}\text { Causas Externas } \\
\text { Quedas, acidentes de trânsito e } \\
\text { agressões. }\end{array}$ \\
\hline 6 & $\begin{array}{l}\text { Descrever as características dos atendimentos de emergência } \\
\text { agrupados na categoria "outros acidentes" do Inquérito VIVA } \\
\text { 2009, em serviços públicos de Teresina (PI). }\end{array}$ & $\begin{array}{l}\text { Do total de } 2.061 \text { atendimentos por causas externas, } 677(32,9 \%) \text { foram por causa de "outros } \\
\text { acidentes", dos quais } 202(29,8 \%) \text { foram por ferimento com objeto perfurocortante, } 172(25,4 \%) \\
\text { por queda de objeto sobre pessoa/choque de pessoas contra objeto, } 111(16,4 \%) \text { por corpo } \\
\text { estranho e } 70(10,3 \%) \text { em razão de acidentes com animais. }\end{array}$ & $\begin{array}{l}\text { Causas Externas } \\
\text { Lacerações, contusões/ } \\
\text { esmagamentos e animais } \\
\text { peçonhentos. }\end{array}$ \\
\hline 7 & $\begin{array}{l}\text { Objetivou-se verificar o perfil clínico-epidemiológico dos } \\
\text { pacientes admitidos na UTI pediátrica e adolescente do Hospital } \\
\text { Metropolitano de Urgência e Emergência de Belém (PA), no ano } \\
\text { de } 2010 .\end{array}$ & $\begin{array}{l}\text { Nos } 132 \text { prontuários, observou-se que o sexo masculino foi o mais prevalente com o trauma } \\
\text { sendo a maior ocorrência. O principal diagnóstico de admissão foi o trauma cranioencefálico } \\
(36,4 \%) \text {, seguido de politraumatismo }(24,2 \%) \text { e queimaduras }(15,9 \%) \text {. }\end{array}$ & $\begin{array}{l}\text { Causas Diversas } \\
\text { Traumatismo cranioencefálico } \\
\text { (TCE) e queimaduras. }\end{array}$ \\
\hline 8 & $\begin{array}{c}\text { Verificar o registro e o número de casos de tentativa de suicídio } \\
\text { entre crianças e adolescentes do município de Matozinhos (MG) } \\
\text { que foram atendidos pelos profissionais de saúde do Pronto } \\
\text { Atendimento. }\end{array}$ & $\begin{array}{l}\text { Verificou-se } 136 \text { casos com suspeita de tentativa de suicídio. Considerando-se os dados por ano, } \\
\text { foram identificados } 42 \text { casos em } 2008 \text { (sendo } 15 \text { crianças e } 27 \text { adolescentes); } 54 \text { casos em 2009, } \\
\text { (desses, } 19 \text { eram crianças e } 35 \text { adolescentes); e em } 2010 \text {, os registros mostraram } 40 \text { casos (nove } \\
\text { crianças e } 31 \text { adolescentes). }\end{array}$ & $\begin{array}{l}\text { Causas Externas } \\
\text { Tentativa de suicídio }\end{array}$ \\
\hline 9 & $\begin{array}{c}\text { Descrever as características das violências praticadas contra os } \\
\text { adolescentes, segundo dados demográficos, tipos de agressores } \\
\text { envolvidos, locais de ocorrência, além de estimar associação } \\
\text { entre as variáveis. }\end{array}$ & $\begin{array}{l}\text { Os adolescentes do sexo masculino, entre } 15 \text { e } 19 \text { anos, foram vítimas mais frequentes, } \\
\text { especialmente em vias públicas. Os meios de agressão predominantes foram força corporal, } \\
\text { espancamento, armas de fogo e envenenamento. No caso das mulheres, o local de agressão mais } \\
\text { frequente foi a própria residência. Em adolescentes de } 10 \text { a } 14 \text { anos, houve mais ocorrências na } \\
\text { escola. }\end{array}$ & $\begin{array}{l}\text { Causas Externas } \\
\text { Lesões por arma de fogo, } \\
\text { lacerações e fraturas por } \\
\text { agressão. }\end{array}$ \\
\hline
\end{tabular}




\begin{tabular}{|c|c|c|c|}
\hline 10 & $\begin{array}{c}\text { Analisar os dados de crianças e adolescentes vítimas das } \\
\text { distintas formas de violência, registrados no Sistema de } \\
\text { Vigilância de Violências e Acidentes/VIVA/MS, de Feira de } \\
\text { Santana (BA). }\end{array}$ & $\begin{array}{l}\text { Crianças e adolescentes foram molestados por diversas violências, como uso de força corporal, } \\
\text { ameaça verbal e armas. Aproximadamente, } 35 \% \text { foram hospitalizados e } 15 \% \text { evoluíram a óbito. } \\
\text { A violência física apresentou maior frequência entre os adolescentes do sexo masculino, já a } \\
\text { violência sexual ocorreu com maior proporção entre adolescentes do sexo feminino. }\end{array}$ & $\begin{array}{l}\text { Causas Externas } \\
\text { Agressões, abuso sexual e lesão } \\
\text { por arma de fogo. }\end{array}$ \\
\hline 11 & $\begin{array}{l}\text { Descrever o perfil dos atendimentos por violência em serviços } \\
\text { de urgência e emergência de capitais brasileiras. }\end{array}$ & $\begin{array}{l}\text { Do total de atendimentos por violência }(\mathrm{n}=4.406) \text {, a maior prevalência ocorreu entre jovens de } \\
20 \text { a } 39 \text { anos }(50,2 \%) \text {, do sexo masculino, negros e de baixa escolaridade. }\end{array}$ & $\begin{array}{l}\text { Causas Externas } \\
\text { Agressões e violência. }\end{array}$ \\
\hline 12 & $\begin{array}{l}\text { Identificar as características demográficas e clínicas das } \\
\text { tentativas de suicídio em adolescentes que visitam o } \\
\text { Departamento de Emergência em comparação com as dos } \\
\text { adultos. }\end{array}$ & $\begin{array}{c}\text { Entre os adolescentes, os que tentaram suicídio apresentaram maior número de antecedentes } \\
\text { de tentativas do que os adultos. Os adolescentes usaram métodos menos letais, como } \\
\text { envenenamento medicamentoso. }\end{array}$ & $\begin{array}{l}\text { Causas Externas } \\
\text { Tentativas de suicídio }\end{array}$ \\
\hline 13 & $\begin{array}{c}\text { Identificar as tendências em lesões não fatais entre jovens } \\
\text { tratados pelo Departamento de Emergência (DE) nos Estados } \\
\text { Unidos, por meio do Programa Eletrônico de Vigilância de } \\
\text { Lesões Nacional (NEISS-AIP). }\end{array}$ & $\begin{array}{c}\text { Em 2015, aproximadamente } 485.610 \text { jovens foram tratados por lesões relacionadas a agressões. } \\
\text { As taxas foram maiores para adultos jovens de } 20 \text { a } 24 \text { anos }(1.376,5) \text { do que para pessoas de } 10 \\
\text { a } 14 \text { anos }(461,7) \text { e } 15 \text { a } 19 \text { anos }(1.159,7)\end{array}$ & $\begin{array}{l}\text { Causas Externas } \\
\text { Agressões e violência. }\end{array}$ \\
\hline 14 & $\begin{array}{c}\text { Quantificar o número de adolescentes e jovens atendidos } \\
\text { no Departamento de Emergência Nacional (NEDS) por } \\
\text { uso indevido de opioides. }\end{array}$ & $\begin{array}{c}\text { Entre } 2005 \text { e } 2014 \text {, as urgências relacionadas ao uso de opioides e as consultas de } \\
\text { emergência aumentaram na faixa etária de } 1 \text { a } 24 \text { anos. A taxa de internação e consultas } \\
\text { de emergência por } 100.000 \text { pessoas aumentou de } 40,6 \text { para } 67,4 \text { e de } 52,4 \text { para } \\
96,7 \text {, respectivamente, nesse período. }\end{array}$ & $\begin{array}{l}\text { Causas Externas } \\
\text { Intoxicação por drogas. }\end{array}$ \\
\hline
\end{tabular}

Fonte: Adaptado de: Garcia APRF, Freitas MIP, Lamas JLT, Toledo VP. ${ }^{10}$ 
Pode-se supor, a partir desse dado, que as tecnologias de informação e comunicação são fundamentais para a obtenção pragmática de informações confiáveis sobre saúde.

As plataformas virtuais são importantes fontes de dados devido à diversidade informacional e documental que hospedam em seus acervos, subsidiando o desenvolvimento tecnológico e científico em Saúde, além do planejamento, implementação e avaliação de políticas públicas. ${ }^{3}$ Vale ressaltar que o acesso a essas informações/ dados é restrito e confidencial, amparado pela Lei Geral de Proteção de Dados Pessoais (LGPD), Lei n ${ }^{\circ}$ 13.709/2018, cujo objetivo é proteger a privacidade e os dados pessoais dos pacientes, inclusive em meios digitais. Portanto, todos os pesquisadores autores de artigos elencados nessa revisão recorreram a procedimentos legais de autorização e consentimento para desenvolver seus estudos.

As principais situações de urgência e emergência entre os adolescentes e adultos jovens detectadas na revisão foram aquelas ocorridas por causas externas. Dentre elas, pode-se citar os acidentes, incluindo acidentes de trânsito, quedas, agressões violentas, incidentes com armas de fogo, cortes e lacerações, intoxicação por drogas ilícitas, tentativas de suicídio, entre outras. Esse resultado corrobora outros estudos semelhantes a esse, segundo os quais as causas externas são o principal motivo de morbimortalidade em adolescentes e adultos jovens, com cerca de 875.000 mortes anuais, de acordo com estimativa da OMS. ${ }^{5}$

Em relação às causas externas estudadas, a violência se destaca quando comparada às outras, manifestando-se por meio de agressões, acidentes com armas de fogo, abuso sexual, perfurações e traumas por golpes. Segundo dados do Instituto Brasileiro de Geografia e Estatística (IBGE), de $2016,{ }^{24}$ os adolescentes e jovens são os mais afetados pela violência no Brasil. No ano de 2014, por exemplo, a taxa de homicídios por arma de fogo para cada 100.000 habitantes era aproximadamente 49,6, no caso de adolescentes e jovens. Pode-se supor que esses índices estejam relacionados à violência urbana e policial, ao porte ilegal de armas, à pobreza, ao racismo, aos baixos níveis de escolarização formal, à limitação de acesso à informação, às más condições de moradia, às famílias numerosas e à ausência de políticas públicas direcionadas à garantia do bem-estar, da justiça social e da saúde dos mais vulneráveis. Considera- se imprescindível que exista um enfrentamento às diversas formas de violência contra adolescentes e jovens, assegurando-lhes o acesso a oportunidades e a salvaguarda dos seus direitos para que, dessa forma, melhorem suas condições socioeconômicas e aperfeiçoem sua formação intelectual e cultural.

Os acidentes de trânsito também se revelaram como causas externas bem recorrentes entre os adolescentes e jovens, resultando em contusões, traumas e óbitos. Provavelmente, isso está associado ao desrespeito às legislações, à imprudência dos motoristas que transitam sem habilitação, ao alto número de motocicletas nas vias, ao não uso do capacete, além da ingestão de bebidas alcoólicas ou outras drogas durante a condução de veículos. Todos esses fatores reforçam a necessidade de criar e difundir estratégias formativas e políticas públicas de educação no trânsito e fiscalização quanto ao cumprimento dos regramentos de segurança.

Observou-se maior predominância de vítimas do sexo masculino tanto nas urgências por violência quanto naquelas por acidentes de trânsito. Esse fato pode ser justificado por questões culturais, uma vez que, em contextos sociais marcados por códigos e diretrizes patriarcais e sexistas, os meninos e adultos jovens são estimulados, ou mesmo condicionados, a executar atividades associadas à "maior liberdade" e/ ou à maior exposição a situações de risco. ${ }^{4}$

Dois estudos ${ }^{21,22}$ alertaram para os altos índices de urgências e emergências entre adolescentes e jovens causadas pelo uso indiscriminado de drogas ilícitas, mais especificamente por intoxicações com opioides. Essas descobertas cumprem a função de alertar os setores da sociedade acerca da facilidade com que esse público parece ter acesso e consumir determinadas drogas de maneira abusiva e sem acompanhamento especializado. Pode haver também relação entre esse dado e a precarização das políticas públicas de Educação em Saúde na escola e fora dela. Por exemplo, discutir saúde na escola reduzindo-a ao incentivo à pratica esportiva, sem algum tipo de orientação e/ou acompanhamento, pode favorecer a busca clandestina de adolescentes e jovens por compostos químicos psicoativos, o que pode causar prejuízos irreparáveis. $^{3}$

Nessa revisão, identificou-se as tentativas de suicídio, entre adolescentes e jovens, como uma das principais ocorrências de urgência e emergência nesse grupo populacional. Trata-se de um dado relevante que, infelizmente, ratifica conclusões de 
outros estudos, segundo os quais o suicídio está entre as 20 maiores causas de morte mundiais para todas as idades. Note-se que, a cada 40 segundos, uma pessoa comete suicídio no mundo e essa taxa aumenta dramaticamente entre os adolescentes e jovens, que, na contemporaneidade, constituem o grupo de maior risco nesse tipo de violência. ${ }^{5}$ Essa predominância pode estar associada à grande falta de informação por parte dos adolescentes e jovens sobre os agravos mentais, que crescem em número a cada dia. Na faixa etária em questão, falar sobre saúde mental pode ser considerado um tabu, o que reveste o tema de preconceito e dificulta as ações de prevenção, proteção e promoção da saúde mental dos adolescentes e jovens.

Essa discussão negrita a necessidade de maior atenção por parte dos serviços de saúde, na tentativa de proteger e evitar a exposição de adolescentes e jovens aos diversos riscos e situações de urgência e emergência. Como ações a serem desenvolvidas, pode-se citar: capacitação dos profissionais em saúde para acolher e atender esse público, desenvolvimento de tecnologias educativas leves-duras, promoção de ações de assistência voltadas aos adolescentes e jovens e intensificação de medidas de prevenção aos agravos em saúde.

\section{CONCLUSÃO}

Nesse estudo de revisão, foram identificados e sintetizados artigos que abordam as principais urgências e emergências entre adolescentes e adultos jovens, motivadas, em sua maioria, por causas externas associadas a acidentes, em especial de trânsito, quedas, agressões violentas e abuso sexual, além de tentativas de suicídio e intoxicações pelo uso de drogas ilícitas. Tais ocorrências podem ser evitadas e/ou amenizadas por meio de medidas socioeducativas focadas na prevenção de agravos e promoção da saúde. No levantamento e identificação dos estudos, constatou-se a existência de investigação incipiente sobre a temática, aspecto considerado como uma limitação para a elaboração de trabalhos de revisão integrativa. Desse modo, percebeuse a necessidade de ampliar os estudos na área e desenvolver tecnologias educativas em saúde, do tipo leves-duras, que amparem intervenções junto aos adolescentes e jovens sobre como agir em situações de urgências e emergências.
Em virtude disso, afirma-se que o desenvolvimento de pesquisas sobre o tema é necessário para reduzir a lacuna de estudos na área e impulsionar a realização de ações estratégicas com ênfase na promoção da Educação em Saúde e na prevenção da morbimortalidade entre adolescentes e jovens vítimas de situações de urgência e emergência por causas evitáveis. Com isso, espera-se melhorar a expectativa e a qualidade de vida dessa faixa etária, além de reduzir gastos na Saúde Pública.

Destaca-se, portanto, a importância dos processos educativos para a Saúde, seja por meio de campanhas, orientações ou tecnologias voltadas para os primeiros socorros que contribuam para prevenir e promover a saúde na adolescência e na juventude.

\section{REFERÊNCIAS}

1. Eisenstein E. Adolescência: definições, conceitos e critérios [documento na Internet]. Adolescência e Saúde; 2005 [atualizado em 10 de abril de 2005; citado em 20 de setembro de 2019]. Disponível em: http://www.adolescenciaesaude.com/ detalheartigo.asp?id $=167$

2. Novaes, RR. Juventude e sociedade: jogos de espelhos, sentimentos, percepções e demandas por direitos e políticas públicas. Revista Sociologia Especial: Ciência e Vida 2007;2(1):6-15.

3. Dias IKR, Torres CMG, Lopes MSV, Santana KFS, Rocha RMGS. Causas dos atendimentos de urgência e emergência do público adolescente: revisão integrativa [documento na Internet]. Adolescência e Saúde; 2017 [atualizado em 12 de fevereiro 2017; citado em 18 de junho de 2019]. Disponível em: http://www.adolescenciaesaude.com/detalhe artigo.asp?id=699 4. Malta DC, Mascarenhas MDM, Bernal RTI, Andrade SSCA, Neves ACM, MELO EM, et al. Causas externas em adolescentes: atendimentos em serviços sentinelas de urgência e emergência nas Capitais Brasileiras - 2009. Ciênc Saúde Coletiva 2012;17(9):2291-2304. doi: https://doi.org/10.1590/ S1413-81232012000900011

5. Malta DC, Bernal RTI, Pugedo FSF, Lima CM, Mascarenhas MDM. Violências contra adolescentes nas capitais brasileiras, segundo inquérito em serviços de urgência. Ciênc Saúde Coletiva 2017;22(9):2899-2908. doi: https://doi.org/10.1590/141381232017229.14212017

6. Alves MAG, Cadete MMM. Suicide attempts among children and adolescents: partial or total injury? Ciênc Saúde Coletiva 2015;20(1):75-84. doi: http://dx.doi.org/10.1590/141381232014201.22022013

7. Mendes KDS, Silveira RCCP, Galvão CM. Revisão integrativa: método de pesquisa para a incorporação de evidências na saúde e na enfermagem. Texto Contexto Enferm 2008;17(4):758-764. doi: https://doi.org/10.1590/S0104-07072008000400018

8. Fineout-Overholt E, Stillwell SB. Asking compelling, clinical questions. In: Melnyk BM, Fineout-Overholt E, editors. Evidence-based practice in nursing \& healthcare: a guide to best practice. Philadelphia: Wolters Kluwer, Lippincott Williams \& 
Wilkins; 2011. p. 25-39.

9. Galvão TF, Pansani TSA. Principais itens para relatar Revisões sistemáticas e Meta-análises: A recomendação PRISMA. Epidemiol Serv Saúde 2015;24(2):335-342. doi: https://doi. org/10.5123/S1679-49742015000200017

10. Garcia APRF, Freitas MIP, Lamas JLT, Toledo VP. Nursing process in mental health: an integrative literature review. Rev Bras Enferm. 2017;70(1):209-218. doi: http://dx.doi. org/10.1590/0034-7167-2016-0031

11. Brito JG, Pedroso BRP, Martins CBG. Acidentes domiciliares por forças mecânicas inanimadas em crianças, adolescentes e jovens. Texto Contexto Enferm 2016;25(2):1-9. doi: http:// dx.doi.org/10.1590/0104-07072016004180014

12. Ribeiro AP, Souza ER, Sousa CAM, Freitas MG. Quedas acidentais nos atendimentos de urgência e emergência: resultados do VIVA Inquérito de 2014. Ciênc Saúde Coletiva 2016;21(12):3719-3727. doi: http://dx.doi.org/10.1590/1413812320152112.18452016

13. Gorios C, Souza RM, Gerolla V, Maso B, Rodrigues CL, Armond JE. Acidentes de transporte de crianças e adolescentes em serviço de emergência de hospital de ensino, Zona Sul da cidade de São Paulo. Rev Bras Ortop 2014;49(4):391-395. doi: http://dx.doi.org/10.1016/j.rbo.2013.10.008

14. Dantas GSV, Rios MA, Silva JK, Pereira DC, Fonseca EOS. Perfil dos acidentes motociclísticos atendidos pelo Serviço de Atendimento Móvel de Urgência nos anos de 2014 e 2015 em município baiano. Rev Pesqui Cuid Fundam 2019;11(4):984991. doi: http://dx.doi.org/10.9789/2175-5361.2019.v11i4.984991

15. Pedrosa AAG, Mascarenhas MDM, Costa EM, Cronemberg LP. Atendimentos por causas acidentais em serviços públicos de emergência - Teresina, Piauí - 2009. Ciênc Saúde Coletiva 2012; 17(9):2269-2278. doi: https://doi.org/10.1590/S141381232012000900009

16. Lima GM, Bulhosa FJS, Souza JAR, Gonçalves KLP, Costa LRN, Nicolau MV, et al. Perfil clínico-epidemiológico dos pacientes da unidade de terapia intensiva pediátrica de um hospital referência em trauma na Amazônia. Revista da Universidade Vale do Rio Verde 2016;14(2):13-23. doi: http:// dx.doi.org/10.5892/ruvrd.v14i2.2581

17. Souza CS, Costa MCO, Assis SG, Musse JO, Sobrinho $\mathrm{CN}$, Amaram MTR. Sistema de Vigilância de Violências e Acidentes/VIVA e a notificação da violência infanto-juvenil, no Sistema Único de Saúde/SUS de Feira de Santana-Bahia, Brasil. Ciênc Saúde Coletiva 2014;19(3):773-784. doi: http:// dx.doi.org/10.1590/1413-81232014193.18432013

18. Souto RMCV, Barufaldi LA, Nico LS, Freitas MG. Perfil epidemiológico do atendimento por violência nos serviços públicos de urgência e emergência em capitais brasileiras, Viva 2014. Ciênc Saúde Coletiva 2017;22(9):2811-2823. doi: http:// dx.doi.org/10.1590/1413-81232017229.13342017

19. Lee J, Bang YS, Min S, Ahn J, Kim H. Cha YS, et al. Characteristics of adolescents who visit the emergency department following suicide attempts: comparison study between adolescents and adults. BMC Psychiatry 2019;231(19):1-9. doi: http://dx.doi.org/10.1186/s12888-019-2213-5

20. David-Ferdon CF, Haileyesus T, Liu Y, Simom TR, Kresnow M. Nonfatal Assaults Among Persons Aged 10-24 Years - United States, 2001-2015. MMWR Morb Mortal Wkly Rep 2018;67:141-145. doi: http://dx.doi.org/10.15585/mmwr. mm6705a1

21. Abbasi J. Emergency Department Opioid Misuse Diagnoses Increasing in Adolescents and Young Adults. JAMA2017;318(24):2416-2417. doi: 10.1001/jama.2017.16586. 22. Winkelman TN, Genao I, Wildemam C, Wang EA. Emergency Department and Hospital Use Among Adolescents With Justice System Involvement. Pediatrics 2017;140(5): 1-9. doi: https://doi.org/10.1542/peds.2017-1144

23. Gil AC. Como elaborar projetos de pesquisa. 5. ed. São Paulo: Atlas. 2010. 192 p.

24. Brasil. Instituto Brasileiro de Geografia e Estatística. Síntese de indicadores sociais: uma análise das condições de vida da população brasileira [documento na Internet]. 2015 [atualizado em 13 de janeiro de 2015; citado em 12 de agosto de 2018]. Disponível em: https://biblioteca.ibge.gov.br/visualizacao/ livros/liv95011.pdf
Recebido em: 28/01/2021

Aceito em:03/05/2021

Como citar: CORREIA JUNIOR, Paulo Cesar Teles; QUEIROZ, Maria Veraci Oliveira. Situações de urgências e emergências entre adolescentes e adultos jovens: revisão integrativa da literatura. Revista Interdisciplinar de Promoção da Saúde, Santa Cruz do Sul, v. 3, n. 3, jul 2020. ISSN 2595-3664. Disponível em: <https://online.unisc.br/seer/index.php/ripsunisc/article/ view/16191>. Acesso em: 01 jul. 2020. doi:https://doi.org/10.17058/rips.v3i3.16191 